\title{
Liquefaction Time Measurement
}

National Cancer Institute

\section{Source}

National Cancer Institute. Liquefaction Time Measurement. NCI Thesaurus. Code C142284.

The determination of the amount of the time it takes for a gelatinous or semi-solid substance to change to a liquid. 